\title{
The Relationship between Athletic Abilities of Japanese High School Soccer Players and Their Psychological Skills in Both Athletic Club and School Life Settings
}

\author{
Kohei Ueno \\ Tottori University, Tottori, Japan \\ Email: kohei@uec.tottori-u.ac.jp \\ Received 9 December 2013; revised 9 January 2014; accepted 16 January 2014 \\ Copyright (c) 2014 by author and Scientific Research Publishing Inc. \\ This work is licensed under the Creative Commons Attribution International License (CC BY). \\ http://creativecommons.org/licenses/by/4.0/

\begin{abstract}
To examine the relationship between students' athletic ability and their psychological skills in the athletic club and the school life setting, 99 players from high school soccer teams were administered with the Psychological Skills Inventory for Athletic Clubs and the Psychological Skills Inventory for School Life. Five coaches of the soccer teams evaluated the players' athletic ability, using the Technique, Intelligence and Insight, Personality, and Speed (TIPS) evaluation framework. Structural equation modeling was conducted to test a series of structural models. Psychological skills in the school life setting have a direct effect on athletic ability. In addition, psychological skills in an athletic club setting have an indirect effect on athletic ability through psychological skills in the school life setting. In conclusion, the coach's belief that players who have life skills and can control their daily life must have a high athletic ability was not wrong.
\end{abstract}

Keywords

Life Skills, Psychological Skills, Athletic Clubs, Soccer, Positive Youth Development

\section{Introduction}

Several programs have been carried out with athletes with the goal of facilitating the development of psychological skills such as concentration (Nideffer, 1993) and stress management (Smith, 1989), thereby improving athletic performance. The development of psychological skills to enhance athletic performance is becoming nothing special. 
Sports activities are widespread across Japan through athletic club activities in school (Tamaki, 2003); the development of psychological skills is not exclusive to a sports setting. An outstanding coach who has led his team to high school soccer championships in Japan stresses the importance of discipline and following rules, not only in the players' athletic club activities but also in the school life setting, reasoning that students who take their school lives seriously will also improve their athletic ability (Komine, 2004). One of Japan's national soccer team members mentions that his athletic performance during the games is influenced by psychological skills and habits in the daily life and the sports setting (Hasebe, 2011). Because it is necessary to manage one's time away from sports appropriately in order to ensure the quality of the time one spends in training, it is understood that success in competition is dependent on psychological skills in daily life.

Psychological skills needed to handle troubles in daily life are called "life skills". Life skills are sometimes used interchangeably with social skills. The World Health Organization (WHO, 1994) defines life skills as abilities for adaptive and positive behavior that enable people to deal effectively with the demands and challenges of everyday life; the WHO proposes ten psychological skills, including interpersonal relationships, problem solving, and decision making. Collins, Gould, Lauer, \& Chung (2009) conducted a qualitative study of 10 of the best coaches in high school American football, with the goal of clarifying the methods for teaching life skills. It became clear to them that the majority of the coaches believed that guidance in life skills is necessary for winning.

Although many studies have focused on life skills development through sport (Gould \& Carson, 2008), no empirical studies have explored the relationship between the athletic ability of the athlete and his or her psychological skills in daily life.

If the relationship is clarified, the number of coaches who want to teach psychological skills in school life to students must be increased. This may lead students to success in sport as well as in their school life. Studies about life skills development through sport are also needed. This study, therefore, examined the relationship between students' athletic ability and their psychological skills in the athletic club and school life settings. To address above issue, a hypothesized model (Figure 1) was examined.

At first, students' psychological skills in a sports and a school life setting were expected to be associated with their athletic abilities. Then, psychological skills in a sports setting were expected to have an indirect impact on athletic abilities through psychological skills in a school life setting because of the acquisition of psychological skills in the sports setting were expected to be the basis of psychological skills in the school life setting. Furthermore, we predict that years of participation in soccer will have a direct impact on athletic abilities and an indirect effect through psychological skills in the sports and school life settings. Hodge and Danish (1999) suggested that sports could foster life skills in young people, although this positive effect might not automatically take place by merely participating in a sport. As mentioned below, however, the number of years of soccer participation

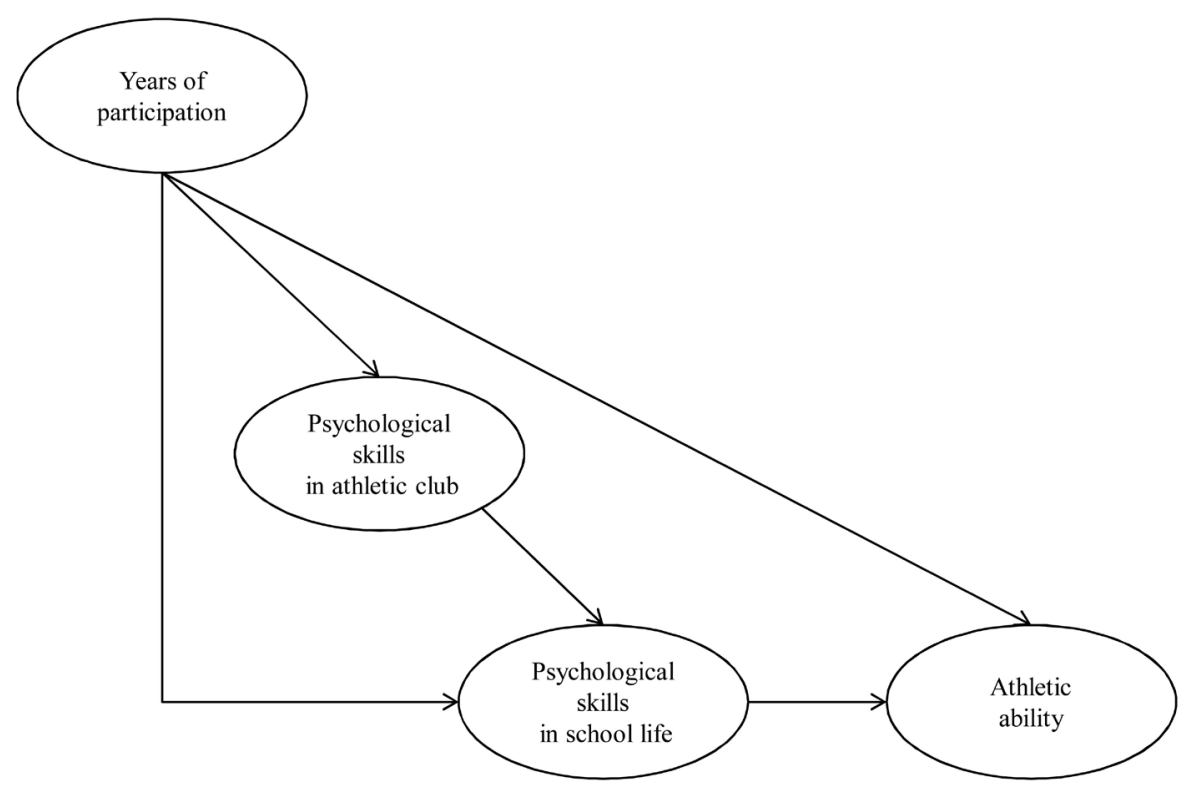

Figure 1. A hypothesized model. 
was expected to be related to psychological skills in school life in the unique situation of Japanese high.

This study was carried out on Japanese high school students who participated in athletic club activities. Athletic club activities in Japan are delineated in government guidelines for education as part of educational activities in school even though they are extracurricular activities. Generally, high school teachers coach school athletic clubs. Compared with school athletic clubs in the United States and the United Kingdom, in Japan, athletic clubs place an emphasis on education (Nakazawa, 2011a). This is particularly common in Japan. Thus, it seemed that Japanese high school athletic clubs' students would be suitable participants for this study, which deals with psychological skills in their athletic club and school life.

\section{Method}

\section{Participants}

The participants were 99 male sophomore and junior soccer players from five high school soccer clubs (mean age $=16.43$ years, $S D=.52$ years) and five male coaches of their clubs (mean age $=33.80$ years, $S D=6.80$ years).

Five high schools were located in the same geographic region. The athletic level of the five clubs was similar. The average number of year of soccer participation of the player was 7.23 years ( $S D=2.11$ years). The average number of years of male soccer team coaching experience was 8.60 years $(S D=4.51$ years). All of the coaches were also teachers in the schools. In all five high schools, the students were free to participate any of the clubs available. None of the high schools had an athletic scholarship program.

The author asked one of the five coaches to find athletic club coaches who would be willing to participate in this research. Although eight coaches were told about this research opportunity, five athletic clubs' players and coaches agreed to participate.

The participants were informed that their participation in the study was voluntary and confidential, and that they would not be penalized in any way if they chose not to participate. Participants were not compensated in any way for taking part in this survey.

\section{Measures}

\subsection{Psychological Skills Inventory for Athletic Clubs}

The Psychological Skills Inventory for Athletic Clubs (PSIA), developed by Ueno and Nakagomi (1998), is a measure of the interpersonal and intrapersonal skills necessary for success in athletic club activities. The PSIA is composed of two subscales: 1) The Interpersonal Skills subscale, which measures the abilities necessary to get along with others in athletic situations; and 2) The Intrapersonal Skills subscale, which measures the abilities needed to achieve personal goals in sports. The PSIA is comprised of 20 questions; there are 10 questions per subscale. Example items include the following: "I traded information with teammates about how to practice," "I acknowledged advice from teammates on my performance," (Interpersonal Skills) "I tried to set specific goals as much as possible," and "I entered every game or match with definite goals in mind" (Intrapersonal Skills). Ueno and Nakagomi (1998) reported internal consistency reliability (Cronbach's $\alpha$ ) values of .65 for the Interpersonal Skills subscale and .77 for the Intrapersonal Skills subscale. The responses for this survey used a Likert scale ranging from 1 (do not apply at all) to 7 (strongly apply). The score for each subscale consists of the sum of the responses to each item. Therefore, each subscale score ranges from 10 to 70 points.

\subsection{Psychological Skills Inventory for School Life}

Ueno and Nakagomi (1998) developed the Psychological Skills Inventory for School Life (PSIS) to measure psychological skills in a school life setting using the same approach as that used for the PSIA. Although some situations differ between athletic club activities and school life settings, both measures were built on the Interpersonal Skills and Intrapersonal Skills subscales. The Interpersonal Skills subscale includes the essential skills needed to get along with others in school life. The Intrapersonal Skills subscale includes the skills needed to achieve personal goals in the school life setting. Sample questions for each of the subscales include the following: "I acknowledged advice from friends about the courses we were taking," "I talked to various friends within the same class," (Interpersonal Skills) "I set short-term and long-term goals," and "I organized my study schedule 
leading up to the dates of regular tests like midterms, etc.” (Intrapersonal Skills). Both subscales contain 10 questions. Thus, the PSIS comprises 20 questions. Ueno and Nakagomi (1998) reported internal consistency reliability (Cronbach's $\alpha$ ) values of .70 for Interpersonal Skills and .71 for Intrapersonal Skills. The responses for this survey used a Likert scale ranging from 1 (do not apply at all) to 7 (strongly apply). The score for each subscale consists of the sum of the responses to each item. Therefore, each subscale score ranges from 10 points to 70 points.

\subsection{Evaluation of Athletic Ability}

Athletic ability of the soccer players was assessed on the basis of the Technique, Intelligence and Insight, Personality, and Speed (TIPS; Kormelink \& Seeverens, 1997) evaluation system, which is used by the Dutch soccer team, Amsterdam Football Club Ajax, to select and train its youth players. Amsterdam Football Club Ajax has a good reputation for developing youth players (Koji, 2000), and their method has been introduced in Japan through instructional tapes (Amsterdam Football Club Ajax, 1996). The TIPS method has been used in Japan to evaluate and select players. TIPS focuses on the following skills: "the ability to control the ball" (Technique); "thinking up plays the opponent cannot predict, and to have the ability to anticipate a play" (Intelligence and Insight); "the ability to communicate with others and to provide leadership, accept teammates, and play with discipline and follow rules" (Personality); and "the ability to have the speed to distance yourself from your opponent instantly and the ability to be able to run long distances" (Speed). TIPS evaluates the athletic ability demanded during actual competition. It was used in this study in order to produce more reliable data than that obtained from self-assessment. Using an average high school soccer player from each coach's past coaching experience as the standard, coaches were asked to evaluate each player with a score ranging from 1 (inferior) to 5 (excellent).

\subsection{Procedure}

All 99 soccer clubs' players completed the PSIA and the PSIS after school. The surveys were implemented by the author in each school. Coaches were asked to leave the room while surveys were being completed. The five coaches were also asked to evaluate the athletic ability of the players that they had personally coached. The evaluation of athletic ability was sent to the author through the mail at a later date. This study was carried out following ethical guidelines of the Japanese society of sport psychology after being approved by the ethics board of the institute to which the author belongs.

\subsection{Analysis}

A series of data analyses were conducted. Preliminary analyses included an examination of the reliability of PSIA and PSIS. In general, the standard minimum level of internal consistency is .70 (Peterson, 1994). According to Ueno and Nakagomi (1998), the internal consistency of the PSIA and the PSIS was a little bit lower than the minimum standard level. First, the reliability of the PSIA and the PSIS were determined using the Cronbach's $\alpha$ coefficients. Then, descriptive statistics and correlations among the study variables were calculated. Finally, structural equation modeling (SEM) was conducted to test a series of structural models to determine whether psychological skills in the sports and school life settings were related to the athletic ability of Japanese high school soccer players. IBM SPSS (PASW) (version 18.0) and Amos (version 18.0) software were used for data analyses.

\section{Results}

\subsection{Preliminary Analysis}

To determine the reliability of the subscales, Cronbach's $\alpha$ coefficients were computed for the PSIA and the PSIS. For the PSIA, the Cronbach's $\alpha$ coefficients for the Intrapersonal and Interpersonal Skills subscales were .85 and .82 , respectively. For the PSIS, the Cronbach's $\alpha$ coefficients for the Intrapersonal and the Interpersonal Skills subscales were .81 and .83 , respectively. Peterson (1994) claimed that the standard minimum level of internal consistency is .70. These values indicate sufficient internal consistency for both factors and both assessments. 


\subsection{Descriptive Statistics}

The descriptive statistics and correlations for the study variables for the full sample of Japanese high school soccer players $(N=99)$ are presented in Table 1 . The skewness and kurtosis values of each of the variables ranged from -.83 to .49 and -.57 to .79 , respectively. There was no missing data.

The correlation between psychological skills in the athletic club setting and psychological skills in the school life setting was generally as expected. Although psychological skills in both types of situation were expected to be correlated with each of the TIPS variables, psychological skills in the athletic club setting were not significantly correlated with any of the TIPS variables. With regard to the relationships between the TIPS variables, only the correlation coefficients between TIPS Personality and other variables (Technique, Intelligence and Insight, and Speed) were lower than expected.

In an attempt to further describe the data, a multivariate analysis of variance (MANOVA) was conducted to explore group differences in terms of grade (sophomore versus junior). The dependent variables were all of the variables presented in Table 1. MANOVA compared sophomores $(n=44)$ and juniors $(n=55)$ on the set of study variables; no significant grade effect was detected (Wilks' $\Lambda(9,89)=.85, p=.08$, partial $\eta^{2}=.15$ ). There was no significant difference between sophomores and juniors in the number of years of participation in soccer, psychological skills in the athletic club setting, psychological skills in the school life setting, and TIPS. Thus, the main analyses were carried out without separating sophomores and juniors.

\subsection{Main Analyses}

SEM was used to test a series of structural models. Hu and Bentler (1998) recommend a two-index presentation strategy to confirm the goodness of fit. One of the combinations of indices is the standardized root mean square residual (SRMR) with the comparative fit index (CFI). In this study, the SRMR and the CFI were used to assess the adequacy of the model's fit, in addition to chi-square testing. Hu and Bentler (1998) have recommended a cut off value close to .95 for the CFI. They also recommended a cut off value close to .08 for the SRMR.

First, a SEM was conducted to examine the relations among the variables in the hypothesized model depicted in Figure 1. The values of goodness of fit indices were $\chi^{2}(22, N=99)=45.965, p<.01$, SRMR $=.059$, and CFI $=.935$. Although both psychological skills in the athletic club setting $(r=.26, p<.05)$ and psychological skills in the school life setting $(r=.38, p<.01)$ were significantly correlated with TIPS, both the coefficient of the path from psychological skills in the athletic club setting to TIPS $(-.08, p=.76)$ and the coefficient of the path from psychological skills in the school life setting to TIPS (.37, $p=.21$ ) were not significant. These results indicated that multicollinearity occurred because there was a strong relationship between psychological skills in the athletic club setting and psychological skills in the school life setting $(r=.81, p<.001)$.

Then, SEM was used to test the modified model, which deleted the path from psychological skills in the athletic club setting to TIPS. The coefficient of the path from psychological skills in the school life setting to TIPS was now statistically significant $(.29, p<.05)$ and the values of the goodness of fit indices were slightly improved $\left(\chi^{2}(22, N=99)=46.056, p<.01\right.$, SRMR $=.059$, CFI $\left.=.937\right)$. However, the coefficient of the path from the years of participation to psychological skills in the athletic club setting was still not significant.

Furthermore, SEM was used to test a final model, which deleted the path from the years of participation to psychological skills in the athletic club setting (Figure 2). All coefficients of the path were significant and the values of the goodness of fit indices were improved $\left(\chi^{2}(22, N=99)=46.056, p<.01\right.$, SRMR $=.060$, CFI $=.939$ ). A final model presented a minimum fit to the data. Latent variables were adequately measured by the observed variables because the maximum and the minimum of the coefficients from observed variables to latent variables was .86 and .58 , respectively.

The results of the final model are illustrated in Figure 2. All parameter estimates are presented in standardized form. First, years of participation had a direct effect on TIPS. It shows that the longer students participate in soccer, the more their athletic ability will be improved. In addition, there was a significant effect from the number of years of participation to psychological skills in the school life setting and from psychological skills in the school life setting to TIPS. It shows that the number of years of participation had a direct effect on TIPS and an indirect effect on TIPS through psychological skills in the school life setting. The longer students participate in soccer, the more their psychological skills in school life will be improved. The more students' psychological skills in school life are improved, the more their athletic ability will be improved. 
Table 1. Descriptive statistics and correlations.

\begin{tabular}{|c|c|c|c|c|c|c|c|c|c|c|}
\hline Latent variables & Observed variables & 1 & 2 & 3 & 4 & 5 & 6 & 7 & 8 & 9 \\
\hline Years of participation & 1. Years of participation & - & & & & & & & & \\
\hline \multirow{2}{*}{$\begin{array}{l}\text { Psychological skills } \\
\text { in athletic club }\end{array}$} & 2. Interpersonal Skills & .04 & - & & & & & & & \\
\hline & 3. Intrapersonal Skills & .05 & $.74^{* * *}$ & - & & & & & & \\
\hline \multirow{2}{*}{$\begin{array}{l}\text { Psychological skills } \\
\text { in school life }\end{array}$} & 4. Interpersonal Skills & $.20^{*}$ & $.62^{* * * *}$ & $.52^{* * *}$ & - & & & & & \\
\hline & 5. Intrapersonal Skills & $.28^{* *}$ & $.48^{* * *}$ & $.61^{* * *}$ & $.65^{* * *}$ & - & & & & \\
\hline \multirow{4}{*}{ Athletic ability } & 6. Technique & $.40^{* * *}$ & .09 & .04 & $.25^{*}$ & $.23^{*}$ & - & & & \\
\hline & 7. Intelligence and Insight & $.29^{* *}$ & $.23^{*}$ & .09 & $.26^{* *}$ & .19 & $.60^{* * *}$ & - & & \\
\hline & 8. Personality & .12 & $.28^{* *}$ & .19 & $.29^{* *}$ & $.21^{*}$ & $.28^{* *}$ & $.51^{* * *}$ & - & \\
\hline & 9. Speed & $.22^{*}$ & $.20^{*}$ & .13 & $.22^{*}$ & $.23^{*}$ & $.62^{* * *}$ & $.65^{* * *}$ & $.53^{* * *}$ & - \\
\hline$M$ & & 7.23 & 51.07 & 46.94 & 50.12 & 46.21 & 3.41 & 3.32 & 3.56 & 3.32 \\
\hline$S D$ & & 2.11 & 7.47 & 9.17 & 8.01 & 8.88 & .87 & .83 & .80 & .87 \\
\hline
\end{tabular}

Note: $M=$ Mean, $S D=$ Standard deviation, ${ }^{*} p<.05,{ }^{* *} p<.01,{ }^{* * *} p<.001$.

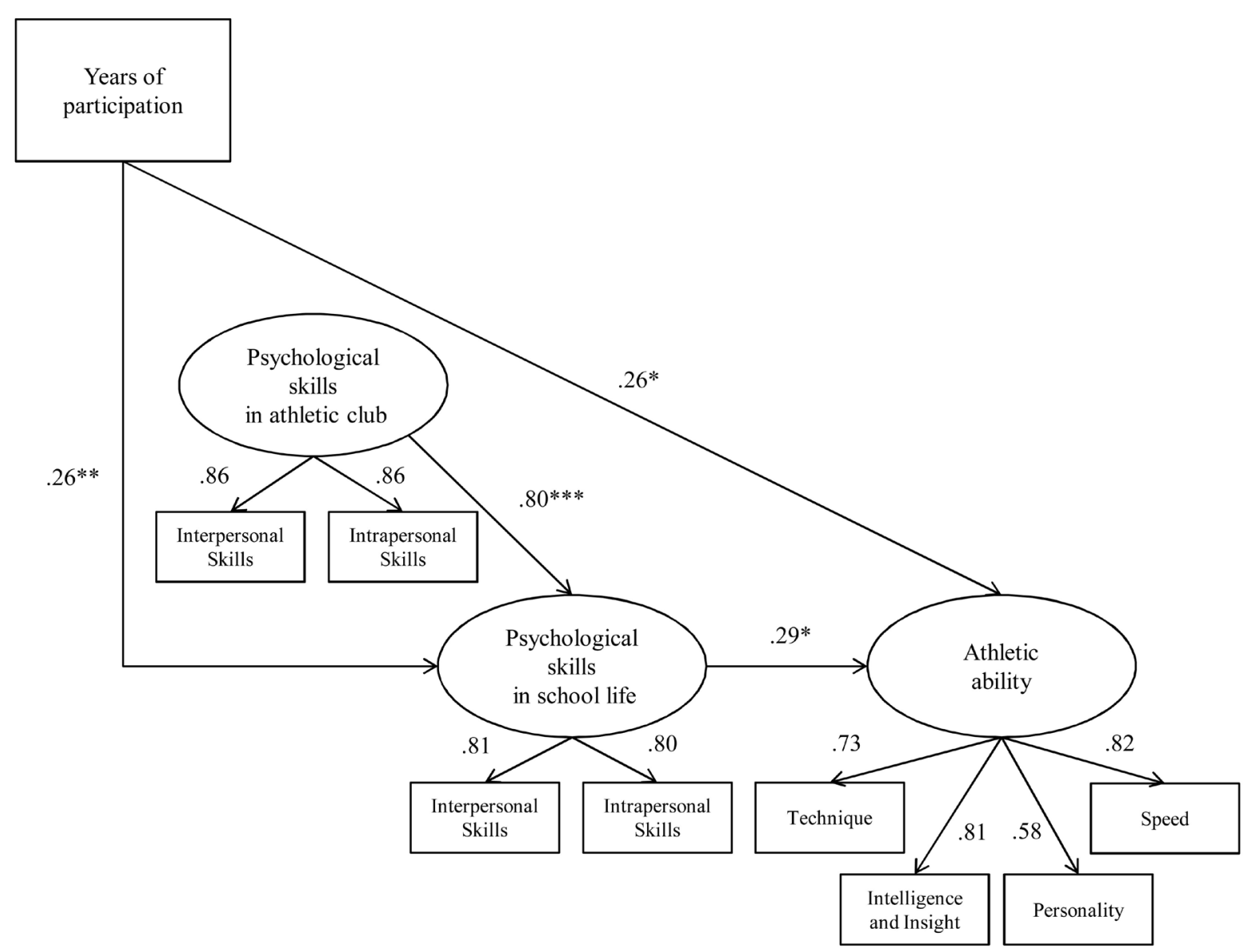

Figure 2. Structural equation model of the final model. The error terms are not presented. ${ }^{*} p<.05,{ }^{* *} p<.01,{ }^{* * *} p<.001$.

Next, the path from the number of years of participation to psychological skills in athletic club was deleted from the hypothesized model. It indicates that the number of years of participation had no effect on psychological skills in the athletic club setting. Additionally, the path from psychological skills in the athletic club setting to TIPS was also deleted from the hypothesized model.

Furthermore, there was a significant effect from psychological skills in the athletic club setting to psychological skills in the school life setting and from psychological skills in the school life setting to TIPS. It shows that 
psychological skills in the athletic club setting had an indirect effect on TIPS through psychological skills in the school life setting. The more students' psychological skills in the athletic club setting are improved, the more their psychological skills in the school life setting will be improved. The more students' psychological skills in the school life setting are improved, the more their athletic ability will be improved.

Finally, although almost all of the coefficients of the path from the observed variables to the latent variables were more than .80 , the value was .58 for TIPS Personality. It showed that TIPS Personality was slightly different from the other variables in TIPS.

\section{Discussion}

The purpose of this study was to determine the relationships between the athletic abilities of Japanese high school soccer players and their psychological skills in both athletic club and school life settings. Psychological scales, which were developed to measure the effect of the psychological skills training on performance enhancement, have basically focused on psychological skills in a sports setting such as concentration, confidence, and anxiety (e.g., Mahoney et al., 1987; Smith et al., 1995; Tokunaga, 2001). Therefore, no empirical studies had explored the relationship between the athletic ability of the athlete and his or her psychological skills in daily life.

The present results suggest that the students who acquired psychological skills in a school setting received higher athletic ability evaluations from their coaches. It has been proposed that the athlete's behavior or their athletic performance might be indirectly influenced by psychological skills in daily life such as communication and lifestyle management skills (Vealey, 1988). The results of the present study indicated that the coach's belief that players who have life skills and can control their daily life must have high athletic ability was not wrong.

The discussion of the relationships among variables in the final model is as follows. First, the path from psychological skills in the athletic club setting to TIPS, which was indicated in the hypothesized model, was deleted from the final model. However, this does not mean that psychological skills in the athletic club setting are not related to athletic ability. It shows that the effect of psychological skills in the school life setting on TIPS was stronger than the effect of psychological skills in the athletic club setting on TIPS. It was thought that psychological skills in the school life setting are more effective predictors of the athletic ability of players than are psychological skills in a sports setting. One of the reasons why the effect of psychological skills in the school life setting on TIPS was stronger than that of psychological skills in the athletic club setting on TIPS is that most of the players who had psychological skills in the school life setting also had psychological skills in the athletic club setting. Players who have psychological skills in both situations can set goals and communicate with others in the school life setting and the athletic club setting. It seemed that players who have psychological skills in the school life setting control many more situations because most of them also have psychological skills in the athletic club setting.

In addition, the number of years of participation in soccer had an influence on psychological skills in the school life but not the sports setting. In previous studies, it was reported that sports could foster life skills in young people; however, this positive effect does not automatically occur by merely participating in a sport (Weiss, 1995; Hodge \& Danish, 1999; Mahoney \& Stattin, 2000). The fact that high school athletic clubs in Japan have been educationally organized to a greater extent compared to other countries may explain why the results of the present study differ from the aforementioned suggestion. As previously mentioned, Japanese high school athletic clubs have been generally managed by school teachers as educational activities (Nakazawa, 2011b). Japanese athletic clubs' coaches are needed to teach not only psychological skills in the sports setting as a coach but also psychological skills in the school setting as a teacher. In fact, many Japanese teachers have a role conflict between coach and teacher (Kubo, 2002). It was guessed that the characteristics of Japanese athletic club activities relate to the abovementioned result.

As for the reason why there was no relationship between the number of years of participation and psychological skills in the athletic club setting, it was thought that players differ from each other in the power of volition to get psychological skills in athletic clubs. It was said that the power of volition of a participant is on top of everything in psychological skills training (Garfield \& Bennett, 1984). There seemed to be players whose power of volition was low and players whose power of volition was high.

Although not a primary focus of this study, transfer from psychological skills in the athletic club setting to psychological skills in the school life setting was expected in the hypothesized model. It may not be easy to 
transfer such skills because many factors such as style of coaching, support from the coach, and negotiations with parents might be related to transferability (Camiré et al., 2009; Jones \& Lavallee, 2009). However, transfer difficulties may show the usefulness of psychological skills in school life as a predictor of the internalization of psychological skills. It seemed that a player who could apply their psychological skills to even different settings must have been able to internalize their psychological skills (Danish et al., 1995). In short, it was thought that they did not just go along with the coach's instruction, because the coach cannot supervise their player all of the time even in a Japanese high school athletic club. It might be hard for coaches to understand how their player can internalize their psychological skills by just checking their psychological skills in a sports setting. However, one might be able to know how a player can internalize their psychological skills by checking their psychological skills in both sports and school life settings.

In this study, the relationship between students' athletic ability and their psychological skills in the athletic club and the school life setting was clarified. There are two major implications of the findings of the present study; they are as follows. First, coaches of youth sports might be motivated to focus on psychological skills in both sports and school life settings. A player can improve their athletic ability by handling their psychological skills in a school life setting. Improving their psychological skills may lead them towards success in the school life setting. Second, the study of life skills development through sport will be enhanced. Gould and Carson (2008) showed the need for studies that deal with the transferability of psychological skills from a sports setting to a daily life setting. Only a few quantitative studies have examined the generalization or transferability of psychological skills from a sports setting to a daily life setting (e.g., Curry \& Maniar, 2003; Goudas \& Magotsiou, 2009). The relationship between psychological skills in a school life setting and athletic ability will lead the researcher, who is interested in the performance enhancement of players, to study life skills development through sport.

The present study has some limitations: the participants were students who belong to Japanese high school soccer clubs. As stated above, Japanese school athletic clubs have some traits that are not seen in school athletic clubs in the United States and the United Kingdom. Specifically, they are carried out as a part of educational activities in school, and almost all of the coaches of the athletic clubs are also school teachers. Future studies should confirm the results of this study in different situations such as athletic clubs that are more recreational or competitive. In addition, TIPS was used to evaluate the athletic ability of the players in this study. It is thought that TIPS, which is an evaluation system of the Amsterdam Football Club Ajax, which is famous for developing youth players, has construct validity with regard to the evaluation of athletic ability in soccer. However, the evaluation of the athletic ability was examined solely by a coach in this study. There are several ways to improve validity, such as evaluation by several coaches or teammates.

\section{References}

Amsterdam Football Club Ajax (1996). The Ajax Soccer Vision. Vol.1: The Ajax Concept. Tokyo: Audio and Visual Network.

Camiré, M., Trudel, P., \& Forneris, T. (2009). High School Athletes’ Perspectives on Support, Communication, Negotiation and Life Skill Development. Qualitative Research in Sport and Exercise, 1, 72-88. http://dx.doi.org/10.1080/19398440802673275

Collins, K., Gould, D., Lauer, L., \& Chung, Y. (2009). Coaching Life Skills through Football: Philosophical Beliefs of Outstanding High School Football Coaches. Journal of Coaching Science, 3, 29-54.

Curry, L. A., \& Maniar, S. D. (2003). Academic Course Combining Psychological Skills Training and Life Skills Education for University Students and Student-Athletes. Journal of Applied Sport Psychology, 15, 270-277. http://dx.doi.org/10.1080/10413200305384

Danish, S. J., Petitpas, A. J., \& Hale, B. D. (1995). Psychological Interventions: A Life Development Model. In S. M. Murphy (Ed.), Sport Psychology Interventions (pp. 19-38). Champaign, IL: Human Kinetics.

Garfield, C. A., \& Bennett, H. Z. (1984). Peak Performance: Mental Training Techniques of the World's Greatest Athletes. Boston, MA: Houghton Mifflin.

Goudas, M., \& Magotsiou, E. (2009). The Effects of a Cooperative Physical Education Program on Students' Social Skills. Journal of Applied Sport Psychology, 21, 356-364. http://dx.doi.org/10.1080/10413200903026058

Gould, D., \& Carson, S. (2008). Life Skills Development through Sport: Current Status and Future Directions. International Review of Sport and Exercise Psychology, 1, 58-78. http://dx.doi.org/10.1080/17509840701834573 
Hasebe, M. (2011). Mental Preparedness [心を整える]. Tokyo: Gentosha.

Hodge, K., \& Danish, S. J. (1999). Promoting Life Skills for Adolescent Males through Sport. In A. Horne, \& M. Kiselica (Eds.), Handbook of Counseling Boys and Adolescent Males (pp. 55-71). Thousand Oaks, CA: Sage.

Hu, L., \& Bentler, P. M. (1998). Fit Indices in Covariance Structure Modeling: Sensitivity to Underparameterized Model Misspecification. Psychological Methods, 3, 424-453. http://dx.doi.org/10.1037/1082-989X.3.4.424

Jones, M. I., \& Lavallee, D. (2009). Exploring the Life Skills Needs of British adolescent athletes. Psychology of Sport and Exercise, 10, 159-167. http://dx.doi.org/10.1016/j.psychsport.2008.06.005

Koji, M. (2000). Football in Nederlands [オランダサッカー強さの秘密]. Tokyo: Sanseido.

Komine, T. (2004). Foster Excellent Personnel through Soccer [国見発サッカーで人を育てる]. Tokyo: NHK Publishing.

Kormelink, H., \& Seeverens, T. (1997). The Coaching Philosophies of Louis van Gaal and the Ajax Coaches. Spring City, PA: Reedswain Videos and Books.

Kubo, M. (2002). Teacher/Coach Re-Examined: Educational Problems of Coaching. Japan Journal of Physical Education, Health and Sport Sciences, 47, 485-490.

Mahoney, J. L., \& Stattin, H. (2000). Leisure Activities and Adolescent Antisocial Behavior: The Role of Structure and Social Context. Journal of Adolescence, 23, 113-127. http://dx.doi.org/10.1006/jado.2000.0302

Mahoney, M. J., Gabriel, T. J., \& Perkins, T. S. (1987). Psychological Skills and Exceptional Athletic Performance. The Sport Psychologist, 1, 181-199.

Nakazawa, A. (2011a). A Comprehensive Review of the Previous Studies Regarding Extracurricular Sports Activity: What Is Known, What Needs to Be Known and What Can Be Known? Hitotsubashi Annual of Sport Studies, 30, 31-42.

Nakazawa, A. (2011b). A Postwar History of Extracurricular Sport Activities in Japan Vol. 1: Focusing on the Transition of the Actual Situation and Policy. Hitotsubashi Bulletin of Social Sciences, 3, 25-46.

Nideffer, R. M. (1993). Concentration and Attention Control Training. In J. M. Williams (Ed.), Applied Sport Psychology: Personal Growth to Peak Performance (2nd ed., pp. 243-261). Mountain View, CA: Mayfield.

Peterson, R. A. (1994). A Meta-Analysis of Cronbach’s Coefficient Alpha. Journal of Consumer Research, 21, $381-391$. http://dx.doi.org/10.1086/209405

Smith, R. E. (1989). Athletic Stress and Burnout: Conceptual Models and Intervention Strategies. In D. Hackfort, \& C. D. Spielberger (Eds.), Anxiety in Sport: An International Perspective (pp. 183-202). New York: Hemisphere.

Smith, R. E., Schutz, R. W., Smoll, F. L., \& Ptacek, J. T. (1995). Development and Validation of a Multidimensional Measure of Sport-Specific Psychological Skills: The Athletic Coping Skills Inventory-28. Journal of Sport and Exercise Psychology, 17, 379-398.

Tamaki, M. (2003). Sports in Japan [スポーツ解体新書]. Tokyo: NHK Publishing.

Tokunaga, M. (2001). Evaluation Scales for Athletes’ Psychological Competitive Ability: Development and Systematization of the Scales. Japan Journal of Physical Education, Health and Sport Sciences, 46, 1-17.

Ueno, K., \& Nakagomi, S. (1998). A Study on the Acquisition of Life Skills through the Participation in Athletic Club. Japan Journal of Physical Education, 43, 33-42.

Vealey, R. S. (1988). Future Directions in Psychological Skills Training. The Sport Psychologist, 2, 318-336.

Weiss, M. R. (1995). Children in Sport: An Educational Model. In S. M. Murphy (Ed.), Sport Psychology Interventions (pp. 35-69). Champaign, IL: Human Kinetics.

World Health Organization (1994). Life Skills Education in Schools. Geneva: WHO. 